\title{
"OS HORMÔNIOS TE SALVAM DE TUDO": PRODUÇÃO DE SUBJETIVIDADES E TRANSFORMAÇÕES CORPORAIS COM O USO DE RECURSOS BIOMÉDICOS
}

Fabíola Rohden

\section{"Não sabia que os hormônios afetavam tanto a vida da gente."}

\begin{abstract}
“Pensei 'tem que ter uma solução no mundo de hoje, uma coisa mais estável' e fui pesquisando... Não sabia que os hormônios afetavam tanto a vida da gente, hoje estou sempre lendo coisas novas, sabendo que sem eles a gente não vive. Sem os hormônios na vida da gente a vida é uma merda, os hormônios te salvam de tudo, tem que manter teu nível hormonal bem para ficar bem.
\end{abstract}

Não pretendo parar, a não ser que daqui a uns cinco ou dez anos o médico diga: você tem um câncer, vamos ter que tirar isso daí! Eu ainda vou pensar se com hormônio eu posso ter mais qualidade de vida que morrer de câncer. Se eu tiver que optar, vai depender da idade. Eu vou preferir tomar hormônios do que fazer uma quimioterapia e estar fodida. Se eu tiver que optar, eu optaria por isso."

Esta epígrafe faz parte da narrativa de uma usuária de implante hormonal que funcionará como ponto de partida deste artigo. O trecho foi escolhido porque sintetiza de forma singular processos como a busca ativa por recursos e a confiança nas soluções biomédicas, a preeminência de uma lógica hormonal no governo dos corpos e da própria vida, a administração pessoalizada dos riscos à saúde e a escolha por assumi-los diante da preferência pela manutenção da "qualidade de vida". Pretendo argumentar que este tipo de atitude pode ser entendido no quadro da produção de formas particulares de subjetividade e transformações corporais que ocorrem a partir do uso de recursos biomédicos. A questão central diz respeito a como as pessoas têm efetivamente lidado com essas possibilidades, assumindo novas maneiras de refletir, procurar e incorporar os tratamentos disponíveis. Este cenário certamente apresenta uma série de diferentes caminhos para investigação. Proponho tratar aqui de um caso específico e a partir dele sugerir interpretações que talvez 
possam ser discutidas em outros contextos. Trata-se do uso de dispositivos de "reposição hormonal" por parte de mulheres com a finalidade de "melhoria da qualidade de vida", o que nem sempre significa busca pela saúde, como pretendo discutir.

O consumo de hormônios por mulheres tem uma longa e polêmica história, na qual se destacam a emergência da pílula contraceptiva e as terapias de reposição hormonal (Oudshoorn 1994; Roberts 2007; Rohden 2008; Sanabria 2016; Faro 2016). Atualmente, várias outras indicações, formas de administração e usos estão em cena, muitas das quais aparentando ou sendo retraduzidas como uma nova promessa tecnológica, que atenderia às necessidades das mulheres contemporâneas. O uso de implantes hormonais para repor ou melhorar a qualidade de vida, especialmente de mulheres com mais idade, pode ser visto dentro desse contexto (Manica \& Nucci 2017; Sanabria 2016). Sugiro que, por uma série de características particulares que tentarei demonstrar, torna-se um objeto bastante relevante de ser explorado.

O fio condutor deste artigo é uma entrevista concedida no escopo de um projeto que pretende investigar processos de subjetivação, transformações corporais e uso de recursos biomédicos. ${ }^{1} \mathrm{O}$ trabalho de campo compreendeu a realização de entrevistas com médicos/as e pacientes/consumidoras de tratamentos hormonais, observações em eventos científicos e acadêmicos, pesquisa em publicações científicas especializadas, sites de associações médicas, agências reguladoras, laboratórios farmacêuticos e farmácias, além de análise de materiais de divulgação de medicamentos e tratamentos médicos e material de imprensa.

A entrevista escolhida chama a atenção porque parece configurar de forma quase exemplar um novo tipo de paciente consumidor/a que tem sido descrito/a na bibliografia dedicada a estudar os processos de biomedicalização da sociedade (Rose 2007; Clarke et al. 2010; Dumit 2012). Utilizo a expressão "quase exemplar" porque, embora pareça estar em sintonia com estas discussões, também aponta para especificidades ou deslocamentos que merecem ser analisados com atenção.

Nos termos de Rose (2007), assistiríamos atualmente à consolidação de uma "ética somática", na qual os valores em torno da vida estariam concentrados no corpo e nas intervenções sobre ele. A valorização de categorias como "bem-estar" e "qualidade de vida", que praticamente justificam qualquer forma de intervenção, seriam indícios desse fenômeno. Nesse processo, as pessoas passam a se definir enquanto "indivíduos somáticos", cujas experiências, articulações, julgamentos e ações sobre si mesmos ocorrem por meio da linguagem biomédica. O conceito de subjetivação, tal 
como apresentado por este autor, remete ao processo pelo qual o sujeito é levado a acreditar que o cuidado com a saúde é uma questão pessoal, de autogerenciamento e responsabilidade.

Como bem descreve Dumit (2012), ao tratar da sociedade norte-americana, cada vez mais as pessoas estão sendo levadas, por meio de uma série de processos complexos mas intensamente atrelados aos interesses das indústrias farmacêuticas, a assumir um papel enquanto (pré)pacientes responsáveis pelo gerenciamento precoce dos riscos e dos recursos associados à manutenção da saúde. Neste cenário, o estado normal dos indivíduos seria uma eterna preocupação com o risco ou com aquilo que não se sabe sobre o próprio corpo. Segundo ele, identifica-se a emergência de um novo tipo de sujeito, o "sujeito-paciente", que indicaria como a apropriação do conhecimento biomédico transforma a própria percepção do indivíduo sobre si mesmo.

Para o autor, trata-se da conformação de novos "estilos de vida farmacêuticos", que não descrevem tipos de pessoas, evidentemente, mas indicam diferentes modos de relacionar informações, riscos, fatos, sintomas etc. Por meio de sua longa investigação, chegou a três modos distintos por meio dos quais os indivíduos se relacionam com a experiência biomédica e os estilos de vida farmacêuticos. O primeiro seria correspondente ao "paciente-especialista" ou expert, que procura se informar e administrar os próprios riscos. Para este, a saúde seria um ideal a ser buscado incessantemente por meio de um estilo de vida saudável e da administração das informações biomédicas. O segundo diz respeito ao "sujeito medroso" (fearful subjetc), que assimila os fatos biomédicos através da pressão e do medo. Neste caso, ser saudável implicaria abdicar dos prazeres da vida que poderiam colocar a saúde em risco. O terceiro modo se refere à experiência de pacientes que acreditam que é preferível viver melhor mesmo que seja à base dos fármacos. Neste último, as drogas seriam uma forma de manter a saúde sem precisar abrir mão de antigos hábitos, mantendo o estilo de vida anterior (Dumit 2012).

Esse processo crescente de autorresponsabilização e incorporação do conhecimento e recursos biomédicos é definido por Dumit (2012:28) em termos de uma autoconstrução objetiva (objective self fashioning). Trata-se, em sentido amplo, de uma redefinição das experiências individuais em virtude do acesso às informações biomédicas. Este fenômeno estaria associado à própria natureza do que descreve como a "vida social do fato médico": um processo de mão dupla no qual, por um lado, o fato médico é incorporado à vida da pessoa e, por outro, a pessoa passa a entender a si mesma diferentemente e objetivamente enquanto objeto daquele fato (Dumit 2012:28).

Certamente, estas proposições são centrais para analisarmos os distintos tipos de engajamento das pessoas com os recursos disponíveis atualmente. 
"OS HORMÔNIOS TE SALVAM DE TUDO": PRODUÇÃO DE SUBJETIVIDADES E TRANSFORMAÇÕES CORPORAIS COM O USO DE RECURSOS BIOMÉDICOS

Porém gostaria de ressaltar a necessidade de considerarmos mais detidamente a dimensão das relações com as diferentes qualidades e materialidades envolvidas nos processos de diagnóstico e tratamento e sua articulação com a produção subjetiva, entendida aqui enquanto a forma pela qual o sujeito percebe e reflete acerca de si mesmo e de sua trajetória, incluindo todas as dimensões envolvidas na sua corporalidade e os variados recursos possivelmente incorporados.

Pretendo argumentar que a produção deste tipo de subjetividade contemporânea que se constitui também pela incorporação de artefatos biomédicos precisa ser entendida enquanto um processo complexo e contínuo, no qual dimensões discursivas e materiais não podem ser pensadas separadamente. Trata-se, portanto, em um primeiro plano, de algo que é produzido por meio de práticas de engajamento e não de algo pressuposto como um $a$ priori. A inspiração para este argumento vem de abordagens centradas na ideia do real sendo performado (ou enacted) a partir de diferentes práticas, tal como concebe Mol (2002). A ênfase passa a ser a inseparabilidade entre o que seria da ordem linguística ou significativa e o que seria da ordem material. Como sugere Haraway, ao conceber a noção de atores materiais semióticos, corpos e significados são produzidos ou materializados provisoriamente em virtude de suas interações no mundo e em função desta ordem de interferências e fronteiras instáveis é que devem ser analisados (Haraway 1995:41). ${ }^{2}$

Mais especificamente, seguindo as contribuições de Barad (2003, 2007) e sua perspectiva de um "realismo agencial", seria impossível predefinir fronteiras entre os supostos fatores materiais e discursivos, sociais e científicos, humanos e não humanos, naturais e culturais. Do contrário, seria necessário conceber jogos de interferência que permitiriam atribuir agência e historicidade também à matéria e não apenas à linguagem e à cultura. Nesse contexto, "a matéria", enquanto entidade passiva e imutável, fixa e dada ou mero resultado de diferentes processos, cede lugar à noção de processos de materialização. Nos termos da autora:

A matéria é produzida e produtiva, gerada e generativa. A matéria é agentiva, não uma essência fixa ou propriedade das coisas. Materializar é diferenciar, e as diferenças que ganham materialidade importam na produção iterativa de diferentes diferenças. Padrões de diferença mutantes não são nem causa pura nem efeito puro; na verdade, são aquilo que efetua, ou antes performa, uma estrutura causal, que diferencia a causa e o efeito. (Barad 2007:137. Tradução minha).

Para Barad (2007), esses processos de materialização só podem ser compreendidos por meio de "intra-ações". Em contraste com a noção de 
"interação", que partiria de diferentes entidades predefinidas e da relação entre elas, o conceito de intra-ações tentaria dar conta da impossibilidade de demarcar fronteiras precisas ou entidades separadas para além da existência de um determinado "fenômeno". Os fenômenos, por sua vez, são concebidos como:

padrões diferenciais de materialização ("padrões de difração") produzidos através de complexas intra-ações agenciais de múltiplas práticas materiais discursivas ou dispositivos de produção corporal, sendo que tais dispositivos não são meros instrumentos de observação, mas práticas de delimitação de fronteiras - (re)configurações materiais do mundo específicas - que ganham materialidade/ passam a importar [come to matter]. (Barad 2007:140. Tradução minha).

Destaca-se aqui, portanto, a ideia de que os "dispositivos" (ou aparatos) fazem parte do próprio processo de materialização, já que produzem diferenças, em função das difrações que necessariamente sempre acontecem. Ou, dito de outra forma, seriam as próprias "condições de possibilidade" necessárias para que determinados fenômenos possam ser materializados. Enquanto na ciência tradicional os dispositivos seriam meros instrumentos de observação e medição de uma realidade pré-dada, na abordagem adotada por Barad (2007) são sempre produtores de interferências e, portanto, de diferenças, tornando-se constitutivos dos próprios fenômenos. Sendo assim, são as intra-ações que performam as próprias entidades e, desta forma, as suas fronteiras, sempre locais e provisórias, no contexto de um dado fenômeno. São elas que constituem as práticas discursivo-materiais que permitem tanto a produção de sentidos quanto as materializações correspondentes.

Considero esta perspectiva bastante frutífera para dar conta de analisar o caso que se segue. Sugiro que a subjetividade corporificada apresentada por Márcia, como vou chamá-la aqui, ${ }^{3}$ pode ser entendida no quadro de processos de materialização nos quais as dimensões subjetiva, discursiva ou simbólica não podem ser pensadas em separado daquilo que seria definido como orgânico, biológico, bioquímico e mesmo farmacológico. A inseparabilidade destas dimensões ganha destaque quando lançamos mão de uma abordagem que privilegie as intra-ações envolvidas nesses processos, possíveis por meio de determinados aparatos específicos. Proponho que, no caso da narrativa de Márcia, a centralidade da concepção hormonal biomédica, especialmente via a materialização do seu diagnóstico e do seu tratamento, ocuparia este lugar de aparato que permitiria, por sua vez, a emergência da materialização da sua subjetividade com (ou por meio dos) hormônios - o fenômeno em questão. Evidentemente, e pretendo enfatizar isto na análise, trata-se de um processo de materialização (ou seja, sua própria concepção 
acerca de suas transformações junto com efeitos corporais identificados por ela) que só é possível a partir do momento em que ela dispõe e assume esta lógica da centralidade hormonal como meio ou instrumento (aparato) para contar a sua história.

Nesse sentido, torna-se central, do ponto de vista do engajamento teórico-metodológico, que esta análise ocorra a partir do seu relato, necessariamente situado em determinado momento da sua vida. Trata-se de levar em conta a relevância do próprio exercício narrativo empreendido por Márcia e o peso atribuído por ela a distintos eventos e suas consequências. Uma narrativa que, sugiro, está completamente organizada, ou melhor, só existe dessa forma em função do aparato necessário para produzi-la: a incorporação da lógica e dos artefatos centrados na preeminência hormonal para a redefinição de sua própria subjetividade.

Em razão desses argumentos, este artigo segue a estratégia de manter uma aproximação atenta com a forma pela qual Márcia optou por apresentar a sua trajetória. Contudo, em paralelo, pretendo introduzir as discussões pertinentes advindas da bibliografia sobre este campo. Gostaria de chamar a atenção especialmente para como, desta maneira, este caso possibilita articular dimensões como gênero e processos de materialização, tão relevantes para analisar a relação entre biomedicalização e produção de subjetividades.

\section{"Minha vida é antes do implante e depois do implante."}

Márcia foi contatada em agosto de 2016 por meio da indicação de uma médica ginecologista brasileira, também entrevistada para a pesquisa. Esta médica sugeriu entrevistá-la quando perguntada sobre mulheres que estariam fazendo o uso de tratamentos com o hormônio testosterona. Márcia é uma brasileira que, no momento da entrevista, tinha 48 anos e morava no México há quase uma década. Considero este fato relevante, pois ao mesmo tempo em que singulariza a trajetória de Márcia, aponta para uma série de conexões e passagens que se dão no plano internacional e que podem fazer parte da busca por recursos biomédicos atualmente. Ela é empresária e avalia que vive muito bem por meio do seu próprio negócio. Já foi casada e tem um filho. Foi muito solícita em conceder a entrevista por Skype porque, segundo ela, gosta de ajudar e contar sobre a sua experiência com o tratamento hormonal. É usuária de um implante hormonal subcutâneo destinado a tratar uma ampla gama de problemas surgidos nos últimos anos de sua vida, o que irei detalhar adiante. Menciona a presença de progesterona, estradiol e testosterona no implante, 
o que é confirmado no material publicizado pela clínica que fabrica estes dispositivos. Embora a menopausa apareça como uma referência importante neste quadro, não é concebida como a origem dos problemas. Márcia revela uma compreensão bastante complexa e elaborada acerca da relação entre as mudanças ocorridas em sua vida e as transformações corporais percebidas por ela.

Espontaneamente, propôs que "daria uma introdução" acerca de como tinha chegado a este tratamento. Esta atitude e toda a sequência da entrevista mostram que se trata de alguém que organiza de forma ordenada a narrativa sobre sua trajetória de vida e contextualiza as tomadas de decisão com base em uma série de informações e avaliações. Segundo ela, poucos anos antes havia decidido se separar do marido e resolvera então se preparar financeiramente para isso. Conseguiu o que desejava, mas esse foi um período muito difícil, "os piores meses da [sua] vida", no qual emagreceu 15 quilos, desenvolveu um problema na tireoide e "consequentemente", conforme disse, entrou na menopausa. Já fazendo referência e corroborando o que afirmou seu médico norte-americano, "uma coisa desencadeou outra: problemas psicológicos, problemas na tireoide, problemas hormonais que confundiram meu corpo". É preciso destacar a maneira pela qual esta conjunção de problemas é apresentada. Trata-se de um estilo de discurso em que não fica evidente de maneira nítida qual seria o sentido (se é que haveria somente um) desta cadeia de associações. O que prevalece, de qualquer jeito, é uma forte correlação entre o que seria da ordem psicológica mais geral e da ordem hormonal.

Em uma primeira fase, Márcia procurou uma médica ginecologista que diagnosticou, apesar de sua "ótima saúde" e "controle alimentar rígido", uma "perda hormonal muito grande e hipotireoidismo". Diante disso, começou a "tomar hormônios para a menopausa", apesar de dizer à médica: "eu sou muito contra, mas estou me sentindo muito mal". O "ser contra" está associado ao fato de sua avó ter morrido em decorrência de câncer de mama, o que a levou a "ter medo" e a se "cuidar muito" e "fazer exames".

Começou, então, a tomar um medicamento (comprimido oral industrializado) indicado para reposição hormonal em mulheres na pós-menopausa. Porém, ao consultar um endocrinologista, foi informada de que, apesar de estar com a "saúde 100\%", teria que usar um outro remédio para tireoide. Nos dois primeiros meses usando estes dois medicamentos ficou melhor, mas depois "qualquer stress e tristeza me desregulava[m]". Passou um ano "ajustando doses, emagrecendo, engordando, com a pele seca; um ano de inferno astral". Segunda ela, já estava "melhor que antes, mas ainda péssima e tendo que tomar dois remédios por dia", o que não gostava. 
"OS HORMÔNIOS TE SALVAM DE TUDO": PRODUÇÃO DE SUBJETIVIDADES E TRANSFORMAÇÕES CORPORAIS COM O USO DE RECURSOS BIOMÉDICOS

Este desconforto de "tomar os dois remédios por toda a vida" foi o que motivou sua procura por outras opções. Pesquisou na internet sobre "coisas novas para problemas hormonais" e "melhoria de vida". Foi então que encontrou um médico, que chamarei aqui de Dr. Roberto, clínico geral e geriatra, nos Estados Unidos. Segundo ela, o próprio médico "desenvolveu toda a pesquisa", um estudo que "tem uns 20 anos", e estava "desenvolvendo um remédio relativamente novo, biomedicina, um remédio nuclear, uma medicina nova". Aqui vale ponderar que não se trata necessariamente do uso de artefatos que seriam os mais inovadores no campo, porém são apresentados pelos profissionais e apreendidos de tal forma. No caso de Márcia, esta "medicina nova" ou "nuclear" que qualifica o caráter inovador do seu tratamento contrasta com os aspectos enfatizados pela clínica que produz os seus implantes. No site que apresenta os procedimentos e o tratamento, curiosamente, não é a retórica de sua associação com inovação tecnológica, mas sim a sua antiguidade que ganha destaque. O fato de serem "naturais, seguros e eficazes" é sustentado em razão deste método já ter mais de 70 anos de uso.

Contudo, o processo de busca pelos recursos e as categorias usadas nele, bem como os termos acionados para descrever o tratamento indicam claramente a sintonia de Márcia com o apelo pelas novidades tecnológicas e pela autoridade científica, expressas na ideia de que o médico é também um pesquisador e toda a sua pesquisa estaria "disponível online". Durante toda a conversa, a vinculação com um tratamento e um profissional norte-americanos foi apontada como garantia de qualidade e inovação. Isto em função do fato de ela ter iniciado o tratamento em uma cidade norte-americana (embora depois tenha continuado por meio de consultas periódicas que o médico realizava na Cidade do México), com um médico identificado como norte-americano (embora não tenha sido possível encontrar referências dele nos Estados Unidos, mas apenas no México), que teria vinculações com universidades da Califórnia e de Nova York, e cujo tratamento seria resultado de pesquisas desenvolvidas nos Estados Unidos.

Munida dessas informações, Márcia foi então se consultar com Dr. Roberto nos Estados Unidos e apresentou-lhe uma série de queixas:

Eu cheguei lá com queixa de cabelo e pele seca, seca por dentro e por fora, ressecada, muito cansada, problema de disfunção, alteração, de humor. O remédio da tireoide me desregulava, o remédio do hormônio... Eu perdi massa muscular; eu era definida, fiquei com gordura. Super ruim. Meu organismo não estava bem. Até a retina ressecou, minhas unhas se quebrando, horríveis. Eu me sentia triste, muito mal, angustiada, e eu não tinha motivo para estar tão ruim. 
Diante das queixas e dos resultados dos inúmeros exames apresentados por ela, o médico afirmou que "começou a trabalhar neste setor de disfunção hormonal por ver tanta mulher sofrer e passar tanto trabalho". Nota-se aí que, além das qualificações como médico e pesquisador, agregava-se, para Márcia, seu caráter humanitário e sensível aos problemas femininos. Os exames "minuciosos" apresentados exigiram de Márcia um grande investimento, tanto financeiro quanto físico. Gastou mais de mil dólares para realizá-los, além de ter passado muitas horas em jejum e ter tirado muito sangue. Além disso, os exames tiveram que ser enviados a um laboratório da Cidade do México, já que na sua cidade de moradia "não sabiam" como fazê-los.

Esta introdução oferecida por ela já aponta para uma série de características que têm sido descritas na bibliografia como reveladoras deste modelo de pessoa-paciente-consumidor ativa/o, que se autorresponsabiliza pela busca das informações e dos tratamentos mais recentes e faz grandes investimentos que possibilitem acessar esses recursos (Rose 2007; Clarke et al. 2010; Dumit 2012). Recorrendo novamente a Dumit (2012), a transformação da pessoa em possível paciente e de paciente em consumidor/a seria um aspecto central na forma de nos relacionarmos com a administração da própria vida hoje em dia.

\section{"As mulheres são mais intensas."}

Um aspecto importante na narrativa de Márcia diz respeito à forma como descreve a percepção dos seus problemas e como isso passa pela referência a padrões de gênero e manutenção da juventude. O mais notável reporta à maneira plenamente intrincada ou relacional pela qual apresenta o que só por meio da distância analítica poderíamos chamar de corporal e de subjetivo. Sua percepção em relação tanto às queixas e aos sofrimentos que a levaram a procurar ajuda médica quanto aos resultados obtidos com o tratamento deixa evidente que se trata de uma intra-ação complexa. Não se sabe, e também não parece haver necessidade de identificar isso, tanto por parte dela quanto de Dr. Roberto, se o que atuaria como origem causal ou determinante estaria na sua insatisfação com a vida que levava ou na "defasagem hormonal" diagnosticada:

Ele disse também que: "é muito normal, eu escuto tudo isso de mulheres, que chegam nesta idade e resolvem mudar tudo". No meu caso [...], tinha coisas para eliminar da minha vida. [...] Me dei conta que eu não era feliz, tinha que 
mudar minha forma de viver, gosto de ficar sozinha, preciso da minha solidão para viver melhor, muita coisa me afogando, obrigações que eu não queria mais ter, tudo desencadeou, tudo junto. Ele disse que é bastante normal, pois você resolve que vai melhorar a vida ou deixar como está. Ele escuta isso de $90 \%$ das mulheres, elas sofrem destes problemas.

O que se sabe, portanto, segundo Márcia, e o que atribui ao seu médico é que este tipo de processo atinge uma grande porcentagem de mulheres e estaria profundamente relacionado com o desgaste associado à vida feminina e ao envelhecimento:

A partir dos 35 todo mundo começa a morrer, diminui tudo, carga hormonal [...]. As mulheres, ele me disse, têm mais desgaste, pois menstruam, procriam, são mais intensas em todas as relações da vida, mais intensas que os homens. Eles [os homens] conseguem passar por cima de muitas coisas, não têm o stress de criar filho, cuidar da casa, se preocupar com as coisas que as mulheres têm.

Percebe-se então como a dimensão do gênero aparece de forma relevante aqui, na sua própria visão e na do médico, não só em referência à "diminuição da carga hormonal", o que poderíamos pensar como eminentemente fisiológico, mas também por meio da menção à vida mais intensa e desgastante exigida das mulheres.

Além disso, cabe ressaltar que, quando Márcia fez referência aos sintomas e benefícios associados aos hormônios, as categorias utilizadas na maior parte das vezes referiam-se a atributos tradicionalmente considerados como requisitos de uma feminilidade desejada no seu contexto social. Estar com a pele, cabelos e unhas bonitos, um corpo "sem gordura" e bem definido, ter o desejo sexual recuperado e uma aparência jovem seriam atributos a se conquistar por meio do uso do implante hormonal. ${ }^{4}$ Assim, embora no que se refira às origens dos problemas permaneça uma concepção mais intra-ativa entre várias dimensões, na recuperação do "equilíbrio" almejado o plano orgânico ou da "funcionalidade" física torna-se fundamental.

Parece ser necessário, para a recuperação de uma vida que valha a pena, um certo processo de manutenção biológica do feminino, garantido por meio dos implantes hormonais. Para Márcia, por um lado, é evidente a contextualização dos seus problemas em termos de uma fase da vida, que reconhece ser comum a muitas mulheres e, portanto, uma compreensão de ordem mais abrangente dos fenômenos que descreve. Por outro, a centralidade atribuída aos hormônios atesta a relevância das explicações e do consumo de produtos baseados nessas substâncias para a percepção que tem acerca da sua própria subjetividade. 
Seguindo a argumentação de Butler (1990), é possível observar como o gênero vai sendo performatizado por meio de um processo de recitação contínuo que passa necessariamente pelo corpo. Entretanto, seria importante enfatizar como esse processo pode estar profundamente associado a outros aparatos, como os artefatos biomédicos. E sem a consideração desses recursos e suas muitas intra-ações, especialmente o que definiria aqui como a relação entre uma autopercepção subjetiva e a administração bioquímica de si via artefatos biomédicos, não seria possível compreender como o gênero está se fazendo. ${ }^{5}$

\section{"Ele é totalmente personalizado."}

Retomando a trajetória de tratamento de Márcia, o perfil revelado nos exames indicava que ela era "candidata" ao uso dos implantes hormonais. A passagem de pessoa com queixas para candidata revela uma espécie de nova conquista dela. A primeira teria sido conseguir acessar as informações pertinentes e encontrar o médico e o tratamento adequados. Agora ela poderia continuar sua trajetória em busca da solução de seus problemas. $O$ ser "candidata" indicava também um certo tipo de valorização do fato de que durante toda a sua vida havia se preocupado com a saúde e mantido hábitos regulares, como fica evidente no trecho a seguir: "Ele disse que eu era candidata. Ele não põe o implante em qualquer pessoa. Você não pode estar acima do peso, precisa ter vida saudável."

Ainda no momento da consulta foram feitos novos exames de sangue, desta vez destinados a preparar as dosagens hormonais a serem incluídas no "chip", como ela relata:

Ele faz os exames, são muitos. Ele coloca todos os dados num programa que eles desenvolveram na universidade, na Califórnia. Ele tira sangue na hora, como se fosse um exame de sangue (como de glicose) e coloca o sangue numa plaqueta e regula na hora a quantidade de hormônio que vai no chip, a partir de uma gota de sangue que vai para um gráfico e ele vai ajustando.

Todo esse processo é narrado em termos de precisão e objetividade científica, incluindo até mesmo a menção dela às próprias dosagens e aos valores de referência padrão. Esta precisão vai também ser alocada no dispositivo a ser implantado:

Cada chip que ele coloca é diferente para cada pessoa, possivelmente é isso... Ele faz um ajuste para cada pessoa de acordo com teus problemas, com aquilo que 
você precisa. Por isso que ele pede todos os exames super minuciosos. A partir de todas essas informações ele vai fazendo teu chip. Ele é totalmente personalizado; não é igual em todo mundo. Mas o que você precisa mais, menos, bastante individualizado... Eu gostei muito, pois eu tomava um remédio "genérico", vamos dizer assim, um dia fazia bem, outro mal, pois era uma dose x. Eu gostei muito, pois você sabe que está recebendo um tratamento específico para você.

Essas características, centradas na personalização do implante, desdobram-se também no prosseguimento do tratamento e nos ajustes e nas mudanças de dosagens feitas ao longo do tempo. Segundo Márcia, no início do tratamento Dr. Roberto disse: "agora você precisa de tudo, pois você está desgastada, mas na segunda vez vai ser bem menos, vou ter uma visão do seu quadro hormonal, vai estar como uma pessoa normal". Chegar a este nível "normal" era necessário para que depois fossem produzidos ajustes mais precisos. Suponho que após esta "normalização" inicial seja possível investir na produção e na conquista de uma maior "funcionalidade", de acordo com o conceito sugerido por Marshall (2009), como discutirei mais adiante

Cada implante dura seis meses e a cada três ela faz novos exames e envia os resultados para o médico. Na época da entrevista, já planejava como seria a próxima intervenção, na qual colocaria o segundo implante:

Eu farei uns ajustes, o meu biorritmo é acelerado, meus movimentos internos, e consumiu muito do implante [...]. Em outubro eu reponho com uma carga diferenciada. Os outros pacientes com quem conversei, a maioria delas já estava no terceiro implante. A pessoa emagrece, dorme bem, massa muscular volta. É a capacidade hormonal de quando você tinha 25 anos. Eu já me sinto outra pessoa. Cada implante custa mil dólares, é relativamente caro, mas vale cada dólar, pois a diferença é muito grande.

As referências ao fato de o "chip" ser personalizado e permitir uma carga diferenciada ao longo do tempo, que foram uma constante durante a entrevista, remetem necessariamente à valorização de procedimentos customizados no cenário contemporâneo de desenvolvimento da biomedicalização (Rose 2007; Clarke et al. 2010; Dumit 2012). No caso de Márcia, isto parece fazer parte do reconhecimento do seu intenso processo de busca por um tratamento melhor que, obrigatoriamente, seria menos "genérico" e mais singularizado.

Conforme Manica e Nucci (2017:99) observam, pelo menos no Brasil esse processo de customização está relacionado com as estratégias adotadas pelo médico Elsimar Coutinho. Este médico tem sido um personagem proeminente no desenvolvimento e na comercialização de implantes hormonais 
(inclusive desde a época em que Márcia fez uso deste artefato no Brasil, como tratarei mais à frente), em um contexto de constantes interfaces com o cenário internacional. Diante das dificuldades de patenteamento e industrialização em larga escala, a saída teria sido o investimento em uma fabricação de alto custo, em pequena escala, assim como no atendimento personalizado e elitizado (ou VIP) que realiza em consultórios particulares em algumas capitais brasileiras. Assim como ele, outros médicos conhecidos por tratar mulheres famosas na mídia, especialmente na televisão, vão insistir na capacidade destes dispositivos para individualizar a quantidade e o tipo de hormônios a serem utilizados para cada paciente.

Ao que parece esta lógica tem feito sucesso, como também enfatiza Sanabria $(2009,2016)$ ao investigar a expansão do mercado de implantes hormonais e das farmácias de manipulação que os fabricam em Salvador. Segundo ela, a retórica da personalização, associada à autoridade do médico para prescrever tratamentos diferenciados, estaria ligada ao aumento no número de farmácias. Porém, ao estudar o próprio processo de fabricação dos implantes, fica evidente que esta personalização não se concretiza, já que os dispositivos são produzidos conforme dosagens padronizadas. Além disso, Sanabria (2009) também descreve como o trabalho de produção está longe das imagens de alta tecnologia evocadas. Trata-se de um procedimento altamente artesanal e dependente da percepção e da expertise de cada funcionária que o executa. Considerando os argumentos e os dados destas autoras, é possível sugerir que a fuga da massificação e a busca de um recurso altamente customizado talvez apenas se materializem nas expectativas das consumidoras e nos efeitos correlacionados, mas não propriamente na composição química ou no processo de fabricação do dispositivo.

\section{"Os hormônios regulam tua vida."}

Conforme Márcia, a carga diferenciada e os benefícios associados fizeram valer todos os esforços empreendidos. Depois de quatro dias de uso, já estava se sentindo muito melhor. Na sua opinião, este tratamento foi um verdadeiro "divisor de águas". Embora ainda não estivesse "100\%", já que passou um longo período "muito desgastada", as mudanças eram bastante significativas:

Meu corpo está hidratado. Claro que as marcas de rugas que vieram vão ficar em função do ressecamento, mas meu cabelo está normal, meu cabelo estava curto, agora já cresceu, minhas unhas também, a retina do olho ainda não voltou, uma coisa mais delicada [...]. É um divisor, pois tenho uma vida melhor, 
minha depressão, vontade de chorar, este tipo de coisa passou. O problema de ressecamento, parte interna e externa, tudo, o sexo... Antes eu não me sentia com vontade de nada, só de dormir... Isso tudo mudou, me sinto muito bem e espero que na próxima carga eu me sinta melhor ainda.

Eu faço meus exames... Voltei a ter minha vida saudável. Acordo cedo, trabalho, vou para academia pela noite... A vida voltou a ter um ritmo que eu tinha quando era mais nova. O implante está ligado diretamente com vida saudável [...]. Eu só posso ligar a uma melhor qualidade de vida, com certeza.

Além dessas alterações notadas em si mesma, Márcia também faz referência às mudanças ocorridas com outras mulheres, suas conhecidas, que usam o implante:

Uma delas não faz exercícios, fuma, e está usando faz um ano. Ela tem 55 anos, ela rejuvenesceu, a pele dela tem um super brilho, os cabelos, emagreceu, ela não faz exercício, tá com corpo legal, pele firme. Ela me disse que nunca na vida dela ela vai viver sem isso, pois ela tinha calorões e muita depressão. Ela teve uma super depressão. Aqui as mulheres são muito reprodutivas. As mulheres mexicanas têm muitos filhos, e isso significa saúde para elas [...]. Imagina como pesa para este tipo de pensamento entrar na menopausa. Ela deixa de servir para alguma coisa, para que veio. [...] Quando começou o tratamento estava muito mal, mas hoje ela é outra pessoa também, em tudo! Fisicamente está bem. Imagina: não faz exercício e fuma, uma mulher com pele bonita, cabelo bonito, se sente bem. Ela se sente muito bem e transmite isso.

O outro caso citado é o de uma mulher atleta de triatlo, com 55 anos e "mega saudável" e com um "super corpo", mas que havia entrado na menopausa aos 25 anos. Começou a fazer o tratamento porque "se sentia triste, a pele estava ressecada, cabelo caía... coisas da idade". Mas depois ficou "outra pessoa", aparentando "não ter mais que 40 anos". Márcia conta que gostou do que viu nelas e que os resultados foram excelentes tanto nas outras quando nela mesma, o que a levou a não ter dúvida de que "faria tudo de novo". E mais uma vez, lista uma série de benefícios do tratamento:

Aumenta a libido e desejo sexual, baixa gordura corporal, diminuição de cansaço, mais atenção e claridade de pensamento, melhora memória, ânimo. A pessoa fica mais estável, menos nervosa, menos irritável, tem menos ansiedade. Sensação de bem-estar. E protegem de problemas cardíacos. Os hormônios regulam tua vida.

Nota-se, para além da mudança em relação a sintomas mais específicos, a referência a uma retomada da "vontade" ou da disposição para realizar as 
tarefas cotidianas e cuidar de si. Todos esses aspectos são associados à ideia de juventude e à qualidade de vida, categorias amplamente utilizadas. A esta altura fica evidente que os benefícios almejados e percebidos por Márcia remetem à busca da retomada de uma certa condição de bem-estar que se caracteriza recorrentemente pela menção ao ideal de um corpo jovem.

Nesse sentido, é pertinente trazer à tona a distinção analítica sugerida por Marshall (2009) entre normalidade e funcionalidade. Segundo esta autora, no contexto contemporâneo de grande influência das indústrias de medicamentos, nota-se esta mudança no padrão utilizado para pensar o corpo e suas funções. O binarismo normal/anormal que serviria, por exemplo, para descrever a "normalidade" do envelhecimento enquanto uma fase da vida comum a todos/as teria sido substituído pelo novo par funcional/disfuncional. A partir desse novo padrão, não se trata mais de submeter-se ao curso da vida, mas sim de buscar incessantemente os recursos que serviriam para promover e manter uma funcionalidade constante e sempre passível de ser melhorada. De forma mais específica, Marshall (2009:140-141) afirma que a funcionalidade: a) não requer qualquer relação com a normalidade: novos padrões redefinem o que é estatisticamente normal como disfuncional em função de ideias culturais; b) é postulada pela mensurabilidade e padronização: estados funcionais são aqueles passíveis de quantificação e tradução em termos da relação com os efeitos de um medicamento; c) desmonta o corpo e o fragmenta em termos de sistemas funcionais e efeito dos medicamentos em tais sistemas: genético, hormonal, neuroquímico, vascular; d) é caracterizada pela adaptabilidade a intervenções e, em decorrência disso, pela vinculação com a criação de bioidentidades: cabe ao cidadão biossocial reconhecer seu estado e adaptar-se às intervenções.

Este esquema analítico ajuda a realçar a maneira pela qual Márcia postula a sua busca pela "qualidade de vida" associada à juventude, retratada nas taxas exibidas em seus exames e nos efeitos específicos do implante hormonal. Tudo isso no quadro de um processo de muito empenho em submeter-se às exigências do seu tratamento e a uma autovigilância constante.

Marshall (2009) chama a atenção ainda para como a funcionalidade, ao tornar os corpos disponíveis para uma ampla variedade de técnicas de mensurabilidade, padronização e intervenção, termina por deslocar a imagem da biologia, ou da natureza, como algo completamente distinto e oposto à cultura. Como consequência, a margem de manobra para se intervir nos corpos por meio dos recursos biomédicos torna-se muito maior.

Outro ponto importante é certamente esta ênfase nos sistemas corporais. Como se depreende da narrativa de Márcia, os hormônios passam a ter um lugar de destaque, no governo de praticamente todas as funções fisiológicas 
“OS HORMÔNIOS TE SALVAM DE TUDO": PRODUÇÃO DE SUBJETIVIDADES E TRANSFORMAÇÕES CORPORAIS COM O USO DE RECURSOS BIOMÉDICOS

e mesmo de suas emoções e disposições. Uma intensa predominância é atribuída aos hormônios e à sua capacidade de "regulação", ou produção de uma certa estabilidade, até mesmo da própria "vida". Neste aspecto não se pode deixar de mencionar que os efeitos positivos descritos por ela incluem maior desejo sexual, menor taxa de gordura corporal, menos cansaço, mais clareza de pensamento, menos irritação, nervosismo e ansiedade e mais estabilidade. Estas são características constantemente atribuídas aos homens e especificamente à testosterona na literatura biomédica, como mostram várias análises (Oudshoorn 1994; Hoberman 2005; Rohden 2011). Além disso, a associação entre tratamentos hormonais contendo testosterona e estes benefícios também foi recorrente nas outras entrevistas, bem como na análise de literatura e observações de eventos médicos realizados nesta pesquisa (Rohden 2017). Uma outra usuária de testosterona afirmou, por exemplo, que além de ter aumentado muito a libido, o hormônio teria "dado um rumo" à sua vida. É também nesta direção que aponta o trabalho de Faro (2016), dedicado a investigar os usos de testosterona por mulheres no Brasil. ${ }^{6}$

Menciono estas indicações porque atestam como o discurso em torno dos hormônios, de um modo geral, e também a referência específica aos benefícios associados ao masculino e atribuídos à testosterona têm sido uma constante. E no caso aqui analisado, podem ser igualmente identificados na forma com que Márcia se refere a todo um conjunto de transformações que passaram a redefinir a sua noção de bem-estar e no padrão a ser buscado.

\section{"Eu nem tomo mais remédio."}

Aos excelentes e amplos resultados percebidos por Márcia com o tratamento, juntamente com o fato da valorização de ser um recurso individualizado, acrescenta-se a distinção operada insistentemente por ela entre seu implante hormonal e o uso de "remédios". O fato de o implante "agir sobre todos os hormônios", e o consequente predomínio desses agentes para toda a sua vitalidade (concebida em termos fisiológicos e de disposição física e psíquica), permitiu que ela se livrasse do incômodo de tomar qualquer outro remédio:

Este implante age sobre todos os hormônios, tanto que eu nem tomo mais remédio. Me tirou todos os remédios, não tomo nenhum remédio. Só nos primeiros meses eu tive que tomar a progesterona por 20 dias [...] pois eu estava muito mal. Eu não gosto de tomar remédio nem para dor de cabeça; para mim era muito difícil e isso me moveu muito a buscar uma alternativa. 
O "não gostar de tomar remédio" é mais adiante qualificado em virtude da associação estabelecida entre remédios e envelhecimento:

Pois com implante eu sei que tenho um remédio atuando, mas não tenho aquela coisa de acordar e tomar remédio [...]. Tudo era uma barreira, tinha problemas e ainda tomar remédio, me fazia sentir ainda mais velha do que eu já estava. Chega nesta idade você pensa: você está velha, acabou minha vida, você via seus avós tomando remédios... Puxa vida: eu faço exercícios, me alimento bem, controlo bem a minha vida e agora não adiantou para nada. Claro que tudo fazia parte da tristeza. O médico foi incrível.

Este ponto é relevante porque chama a atenção para a importância de novas dimensões associadas às materialidades do tratamento usado por Márcia. Em primeiro lugar, ela distingue (embora "saiba que tem um remédio atuando") o uso de hormônios do uso de remédios, que estariam relacionados à presença de outras substâncias em sua composição. Por trás disso está a ideia de que os hormônios utilizados seriam "bioidênticos" (conforme insiste a clínica que os fabrica) e que, portanto, não fariam mais do que repor ou regular as necessidades "naturais" do organismo. ${ }^{7}$ Não seria uma questão de acrescentar novas drogas exógenas, mas simplesmente de administrar as dosagens de substâncias já existentes de forma a chegar ao equilíbrio necessário a uma boa "qualidade de vida" ou à funcionalidade da juventude. ${ }^{8}$ Existiria portanto uma proximidade material atribuída à composição dos implantes e aos hormônios produzidos pelo próprio corpo.

Em outro plano a equação formada por hormônios e remédios se materializa pela distinção operada em termos das formas de administração ou consumo. Enquanto o consumo de remédios é associado a uma rotina de ingestão de muitos comprimidos que remete à velhice, o uso do implante é valorizado pela sua não visibilidade. O dispositivo não é aparente na superfície do corpo, assim como não é a sua forma de atuação ou interação com os órgãos internos, a não ser pelos benefícios notados. Sua discrição, por um lado, e sua capacidade de atuação continuada, por outro, são características valorizadas e associadas também à noção de que é um artefato tecnológico moderno e inovador. Aqui é sintomático que problemas ligados à digestão e à assimilação das propriedades das pílulas de ingestão oral não se fazem mais presentes. E a presença das substâncias atuantes via o implante não é notada nesse nível de relação entre sujeito e percepção corporal mais imediata.

Mais ao final da entrevista, quando estava falando sobre a importância dos hormônios na sua vida, Márcia relatou outro episódio que reafirma a distinção feita entre uso de remédios e implantes. Contou que já tinha uma experiência prévia com o uso deste tipo de dispositivo, reconhendo o seu 
“OS HORMÔNIOS TE SALVAM DE TUDO": PRODUÇÃO DE SUBJETIVIDADES E TRANSFORMAÇÕES CORPORAIS COM O USO DE RECURSOS BIOMÉDICOS

papel como "cobaia" do laboratório e as trocas que podem estar implicadas nesse tipo de processo experimental envolvendo tecnologias biomédicas, como poder "ganhar" o segundo implante do laboratório:

Antes eu nem sabia de hormônios, nunca tomei pílula, era bem regulada, nunca gostei de remédio. Fui uma das primeiras pessoas que fizeram o implante subcutâneo no Brasil, a cada seis meses, para não menstruar, vida normal. Fui cobaia do laboratório e ele me deu o segundo. Com 30 [anos] eu parei de tomar, tudo, até o palitinho (como chamavam no Brasil), só usava camisinha, nunca mais pensei nisso, até começar a ficar mal.

Merece destaque o fato de que a pílula contraceptiva é associada a remédio, algo de que ela "nunca gostou", embora seja de conhecimento generalizado que todas as pílulas são compostas de diferentes associações de hormônios. E presumo que Márcia, que é uma pessoa preocupada com a saúde e bem informada saberia deste fato. Digo isto para ressaltar que a forma do dispositivo parece vir à frente na sua definição enquanto remédio, e não a sua composição. Ademais, ela afirma que antes do atual tratamento "nem sabia de hormônios". E que, por não gostar de remédios e da pílula oral, utilizou, de forma pioneira, o implante subcutâneo "para não menstruar", ainda no Brasil, em meados da década de 1990. ${ }^{9}$ Esses implantes também eram de composição hormonal. Mas Márcia parece não reconhecer isto ou, simplesmente, este aspecto não era relevante na sua escolha contraceptiva daquele momento. A impressão que se tem é a de que naquela fase de sua vida não pesava se eram ou não hormônios atuando. O que importava eram os efeitos desejados, de suspender a menstruação e a possibilidade de gravidez que o implante proporcionava.

Isto remete à questão mais abrangente relativa a como os recursos biomédicos e seus efeitos (e possibilidades de risco) são incorporados pelas pessoas, no quadro de produção de suas subjetividades, e em função de contingências ou aparatos específicos. Retomando o argumento de Barad (2007), poderíamos pensar em termos da produção de um novo fenômeno (a materialização de sua subjetividade via a incorporação dos recursos biomédicos) que só foi possível em virtude de um determinado aparato (a adoção da lógica e de artefatos de diagnóstico e tratamento centrados na concepção hormonal no contexto de uma situação particular).

Quanto à dimensão da forma e das propriedades atribuídas ao tratamento de Márcia, outro aspecto que chama a atenção refere-se ao fato de que inúmeras vezes o implante é referido como "chip". Este não é um deslizamento feito ao acaso, mas remete a uma série de associações, especialmente às ideias de alta tecnologia, eficiência e modernidade. Como 
argumentam Manica e Nucci (2017), embora ainda em desenvolvimento e portanto não disponíveis no mercado, os microchips hormonais de silício e titânio, ativáveis por redes de dados digitais, têm ganhado bastante destaque na imprensa, inclusive brasileira, a partir de 2014. Estes dispositivos teriam, em relação aos implantes hormonais tradicionais, a vantagem de uma maior durabilidade (até 16 anos) e possibilidades de administração diária e interrupções planejadas sem a necessidade de sua retirada (Manica \& Nucci 2017:104). Contudo, nas matérias de divulgação estas diferenças são ignoradas e os antigos implantes são descritos e apresentados, inclusive visualmente, como se fossem os novos "chips". Sobre esse processo, concluem:

Podemos dizer, assim, que da perspectiva do mercado brasileiro e do senso comum há uma ênfase na técnica de implantação subcutânea e liberação progressiva de hormônios em detrimento de suas variações tecnológicas, das atualmente disponíveis cápsulas microporosas de silicone aos prometidos microrreservatórios lacrados, (des)ativáveis pela circulação de dados digitais, ou ainda aos chips atualmente utilizados para localização e rastreamento de animais domésticos. O uso do termo "chip" parece conferir aos antigos implantes subcutâneos uma renovação que, embora não seja (ainda) real, é positivada e desejada como se o fosse (Manica \& Nucci 2017:107).

\section{"Riscos na vida a gente corre de todos os jeitos e todas as horas."}

A trajetória de Márcia, portanto, indica de modo singular, o gerenciamento de suas escolhas, dentro das possibilidades que encontrou disponíveis, por meio de conhecimento de certos processos que envolvem a produção e a comercialização de tratamentos biomédicos. Esta característica ilustra de maneira exemplar as habilidades que estão sendo promovidas e exigidas no contexto de crescente responsabilização individual pelos cuidados em saúde e mais especificamente até mesmo da formação de um "paciente experto" (Dumit 2012). Neste cenário, o problema do gerenciamento dos riscos torna-se fundamental, sendo cada vez mais uma atribuição do próprio sujeito.

Quanto a este aspecto, Márcia, mais uma vez, adota uma posição na qual contextualiza e justifica bastante as suas escolhas. As ponderações reproduzidas abaixo vieram à tona inúmeras vezes durante a entrevista (como se pode ver também na epígrafe deste artigo), indicando, dessa forma, como se trata de um dilema importante e cuja decisão, pelo menos nesse momento de sua vida, precisa ser constantemente reafirmada: 
Quando eu resolvi colocar o hormônio, o implante... claro que sei, você corre riscos. Falei com uma médica, é um alimento para uma série de cânceres que nesta idade você pode ter. Mas eu pensei que a vida que eu estava levando... Assim, eu tenho 48 anos e pensei: se eu tiver mais dez anos de vida, podendo viver estes dez anos, eu prefiro viver bem estes dez anos e morrer de câncer do que viver a vida que eu estava levando, que era horrível, um inferno, sabe? [...] Então, decidi que entre uma ou outra eu preferiria ter dez anos de vida útil boa do que passar, viver vinte anos mais e me ferrar.

Os riscos para ela são diretamente associados à possibilidade de ter câncer. Como se nota, a dimensão temporal surge aqui de maneira muito significativa. E se traduz não só nesta distinção entre "viver bem" e "viver muito e mal", como também opera no sentido de distanciar os potenciais efeitos negativos do seu tratamento. Sobre isto contou que, através dos seus exames, soube da existência de alguns miomas (tumores benignos que se desenvolvem na parede do útero). Mas a própria profissional que fez os exames atestou que, caso ela fosse desenvolver um câncer, isso iria demorar. E que o implante hormonal seria "um potencializador para só em cinco ou seis anos aparecer alguma coisa", ao que Márcia respondeu: "então para mim está ótimo!".

Além disso, há também um deslocamento operado entre ter medo de câncer e admitir que os riscos estão em toda parte ou são imprevisíveis. A isso acrescenta uma nova justificativa para o tratamento hormonal, que deixaria o organismo mais forte:

Eu sempre fui 'panicada' com câncer, pois minha avó morreu de câncer super nova [...] e essa foi minha preocupação. Claro que hoje com o resultado eu digo: foda-se se tiver câncer. Riscos na vida a gente corre de todos os jeitos e todas as horas. ${ }^{10}$ Então eu prefiro enfrentar isso com uma fortaleza de saúde melhor, pois eu me alimento super bem, sinto vontade de fazer exercício, me sinto melhor que antes, estou melhor hoje. Se eu tivesse que enfrentar uma barra dessas, eu estaria mais preparada que antes. Eu faço a maior propaganda [do implante hormonal].

Márcia corrobora esta posição com as informações dadas por Dr. Roberto sobre o fato de que "as pacientes dele que vieram a desenvolver o câncer de mama já tinham um organismo mais reforçado e saudável para enfrentar a quimioterapia". Com o uso do implante teriam "um organismo mais preparado" do que aquelas "super desgastadas", "super debilitadas" e com "uma defasagem hormonal".

Na sequência, ela faz referência a outro aspecto que remeteria à segurança do seu tratamento e, portanto, ao acerto de sua escolha. Argumenta que 
nos Estados Unidos, a FDA (Federal Drugs Administration) "controla todo tipo de medicação" e exige, para tanto, longos estudos, como os realizados pelo seu médico. Para Márcia, isto contrasta com o que acontece no Brasil:

No Brasil todo mundo manda na vida da gente sem a gente saber. Vivemos numa bolha. A indústria farmacêutica aí faz muito trabalho com os médicos, eles vendem o que querem. A H1N1 aqui foi muito séria, a vacina acabou aqui no México, mas os EUA socorreram todo mundo aqui [...]. Para o Brasil foi só porcaria, remédio velho, sem validade, vacinas ruins, todo mundo sabia, os médicos sabiam. A vacina que foi para o Brasil não tem efeito. [...] Eles não deixaram entrar... Controlam a opinião dos médicos. Tomar todos os dias, [ao invés] de usar um remédio que toma a cada seis meses [referindo-se ao implante], pode ser interesse deles... Quando tem aprovação do FDA é bom, se não está, você se mete onde quiser.

Nota-se, portanto, que suas decisões são assessoradas por um vasto quadro de informações que passa, inclusive, por comparações envolvendo o cenário internacional de distribuição de medicamentos ou, pelo menos, os recursos e as regulamentações concernentes a México, Brasil e Estados Unidos. Ademais, ressalta-se a ideia de que, em contraste com a "bolha" na qual se vive no Brasil, ela estaria em condições de manejar um conjunto maior de tratamentos e informações, caracterizando, mais uma vez, sua condição ativa no processo de administração e consumo de recursos biomédicos.

Sem dúvida, podemos ver em Márcia a configuração de uma paciente-especialista que incorpora de forma significativa a responsabilização pessoal por suas escolhas. Entretanto, voltando aos tipos de paciente apresentados por Dumit (2012), é importante frisar que as atitudes de Márcia implicam algumas ponderações. Se, por um lado, ela se enquadra no estilo de paciente especialista, tanto pelo seu domínio acerca dos recursos disponíveis quanto pela manutenção de um estilo de vida saudável, por outro, a sua forma de lidar com os riscos remete a algo diferente. A busca pela saúde, tão enfatizada por Dumit (2012), cede lugar ao que poderia ser definido como a busca por uma "qualidade de vida", que pode não se coadunar com a saúde a longo prazo. Sua opção é assumir o risco de vir a desenvolver um câncer futuramente em face dos benefícios associados a uma vida melhor agora.

Mais uma vez a dimensão temporal tem grande importância e conduz à modulação do que seria considerado ser saudável. Márcia afirma que leva uma vida saudável em decorrência de todo o seu autocontrole alimentar, de suas horas de sono, da dedicação a uma rotina diária de exercícios e mesmo de evitar o consumo de remédios. Contudo, este estilo de vida saudável, para poder ser desfrutado, necessariamente precisa vir acompanhado do uso de 
hormônios que, ela mesmo considera, poderiam levar ao seu adoecimento. O risco do qual ela tem ciência é, portanto, deslocado para um futuro distante.

Esta forma de administrar o uso dos recursos biomédicos se assemelha ao que Martin (2006) descreve no processo de transformação dos próprios indivíduos em "pessoas farmacêuticas". Em um contexto, segundo ela, no qual se incentiva o uso de fármacos para que as pessoas se tornem mais "completas", "somos menos sem remédio" (2006:280, grifo da autora). Este cenário prevê que os fenômenos cotidianos sejam definidos em termos médicos ou farmacêuticos, e o aperfeiçoamento passe a ser uma ideia central: não basta apenas "regular" ou "normalizar", também é preciso "melhorar constantemente". O consumo de fármacos, assim, implica também a necessidade de lidar com a sua ambivalência, não só no que diz respeito às qualidades "personalizadoras" atribuídas aos medicamentos, mas também no que se refere aos seus significados positivos ou negativos, expressos nos chamados efeitos colaterais. Neste aspecto, conforme Martin (2006), o que as pessoas comumente fazem é um processo de deslocamento ou purificação em relação aos efeitos negativos: "tirar da vista" os aspectos perigosos. Esta seria uma forma de lidar com a ambivalência que permitiria consumir cada vez mais medicamentos, o que, eu acrescentaria, não implicaria necessariamente uma vida mais saudável, pelo menos a longo prazo.

\section{"Exige muitas coisas para que funcione o implante."}

Para finalizar, gostaria de retomar os argumentos levantados no início deste artigo, agora em face da narrativa de Márcia. A frase que dá título a este último tópico remete ao plano das materializações envolvidas no próprio implante hormonal. Como Márcia mesmo enfatizou, ele "não funciona sozinho". Sua capacidade de agir está intensamente relacionada não só com as substâncias que contém, mas também com sua forma (por contraste com "remédios" ingeridos por via oral) ou seus ajustes à especificidade metabólica de Márcia no decorrer do tempo, por exemplo. Para além disso, é necessário todo um grande investimento dela na manutenção de um estilo de vida saudável ou regular que seria condizente e adequado para o funcionamento do artefato. Como ela mesma disse: "[e]xige muitas coisas para que funcione o implante". Aqui não se sabe bem, pela construção da frase, se muitas coisas são exigidas, em geral, para que ele funcione ou, mais sintomaticamente, se o próprio implante exigiria isto, o que acentuaria ainda mais o seu caráter ativo e demandante. Contudo, o que importa é que fica evidente a necessidade de levar em conta de forma mais efetiva os diversos processos 
de materialização que caracterizam a produção de formas de subjetividade que não existiriam sem intra-ações complexas com os recursos biomédicos.

Se o implante hormonal de Márcia, por um lado, torna-se absolutamente necessário para a sua vida, por outro, ele não age sozinho, demandando uma série de investimentos. Em termos mais gerais, isto conduz à necessidade de reconhecer a importância das materialidades nos processos de subjetivação, porém por meio de uma imprescindível associação com as relacionalidades envolvidas. Como afirma Mol (2012), a matéria nunca age sozinha, portanto, faz-se necessário adotar um tipo de materialismo obrigatoriamente relacional (Abrahamsson et al. 2015).

Tal perspectiva é desenvolvida de forma especialmente pertinente para esta análise no artigo "I eat an apple" (Mol 2008). A sua remissão à discussão acerca das subjetividades por meio de engajamentos com processos eminentemente corporais ajuda a nos aproximarmos do caso aqui tratado, que envolve o consumo de hormônios. Ao recorrer à ideia de um sujeito que "come uma maçã", a autora tenta chamar a atenção para a necessidade de repensarmos as teorias sobre subjetividades. Ao contrário do sujeito tradicional da filosofia, concebido de forma universal e descorporificado, sua proposta é pensar em um sujeito que interage de forma mais complexa com outras materialidades, como os alimentos que ingere e degusta. Dessa forma, não só o enquadramento contextual e histórico é importante (de quem pratica o ato de comer uma maçã específica em um dado contexto particular, por exemplo), como também as dimensões relativas à interação físico-corporal, ao conhecimento, às normas, aos valores e às apreciações envolvidos, que necessariamente fazem parte do processo de produção de subjetividades.

A associação obrigatória entre o conhecer e o avaliar (o gostar ou não gostar; a forma de apreciar), que passa pelos vários processos corporais envolvidos no ato de comer, permitiria entender melhor também o caso aqui analisado. Sugiro que os efeitos concretos narrados por Márcia, tanto na percepção dos seus problemas como nas suas soluções, não possam ser concebidos em separado do seu conhecimento sobre os hormônios, da forma utilizada para incorporá-los via recursos farmacêuticos e de todas as avaliações relativas à customização do tratamento, à autoridade e à legitimidade atribuídas ao médico e ao procedimento, da mesma forma que este conhecimento e as apreciações valorativas não fazem sentido longe dos impactos produzidos pelo implante hormonal em seu corpo e subjetividade.

Para além deste primeiro ponto, gostaria de destacar ainda um aspecto em particular. Embora nos diferentes tópicos apresentados neste artigo muitos temas tenham vindo à tona, como a transformação de Márcia em paciente-especialista, o caráter customizado e personalizado do tratamento, 
a distinção entre implantes hormonais e remédios, o gerenciamento dos riscos e uma singularização via gênero, um marcador é frequentemente mencionado. Trata-se da referência a expressões como "tudo desencadeou", "tudo muda", "hormônio regula tudo" como eixos articuladores fundamentais da sua experiência. Proponho que esta insistência no "é tudo junto" precisa ser levada a sério e não simplesmente considerada como uma generalização comum nos discursos de pessoas (ou pacientes) que, por exemplo, não dominariam bem a compreensão biomédica acerca de corpo e saúde. Talvez o "tudo junto" indique que pessoas como Márcia, que fazem suas apropriações particulares dos artefatos biomédicos, estariam muito mais abertas a concepções afinadas com a ideia de intra-ações do que nossa capacidade analítica, em geral dicotomizante, permitiria imaginar.

É certo que este "tudo junto" concebido por Márcia não equaciona da mesma forma quaisquer fatores. Tanto é que, como argumentei, o diagnóstico e o tratamento hormonal, ou seja, o próprio artefato biomédico que combina recursos de diferentes tipos, do que seria da ordem "discursiva" e "material", pode ser entendido enquanto o aparato que produz a sua subjetividade biomedicalizada. Há aí, portanto, uma preeminência atribuída à lógica biomédica na compreensão que Márcia desenvolve acerca das suas transformações, tanto as negativas, como os sintomas associados a "estar mal", quanto as positivas, vinculadas aos benefícios do tratamento. Mas o interessante é que não há um encerramento dos processos, por exemplo, na capacidade de atuação do implante. E nesse sentido é que os investimentos em torno do engajamento em distintos processos de materialização parecem interessantes, ressaltando que nada estaria dado a priori, mas tudo estaria sempre surgindo nas práticas.

Adotar uma abordagem que siga nesta direção certamente tem implicações na própria maneira como concebemos a realidade (como múltipla ou única, por exemplo) e, assim, consequências no plano político. Se uma certa concepção biomédica mais dura e reducionista restringe tudo a uma ordem fisicalista, é fácil advogar que basta procurar as razões últimas dos fenômenos no plano concebido como natural. Não haveria lugar para dúvidas, mas apenas para uma perspectiva que administra a insuficiência de conhecimento sobre esta realidade única. Entretanto, se de fato levamos a sério a consideração de que "é tudo junto", as incertezas aumentam. Permaneceríamos com a identificação de associações prováveis, possivelmente sempre em cadeias crescentes e cada vez mais complexas de entendimento, sempre com novos desafios, porém jamais definitivas. 
Recebido em 05 de julho de 2017

Aprovado em 07 de março de 2018

Fabíola Rohden é Professora do Programa de Pós-Graduação em Antropologia Social, Departamento de Antropologia, Universidade Federal do Rio Grande do Sul, Porto Alegre/RS, Brasil. E-mail: <fabiola.rohden@gmail.com> 


\section{Notas}

1 Este artigo apresenta resultados do projeto "Processos de subjetivação, transformações corporais e produções de gênero via a promoção e o consumo de recursos biomédicos" apoiado pelo Conselho Nacional de Desenvolvimento Científico e Tecnológico - Brasil (CNPq). Agradeço à equipe que participou da investigação, especialmente à Eleonora Bachi Coelho pela realização da entrevista aqui analisada, e ao apoio de Emerson Giumbelli e Horacio Sivori nos ajustes finais no artigo. Agradeço também a todos/as os/as participantes que se dispuseram a colaborar com este trabalho.

2 Seguindo a linha das contribuições de Haraway, outras autoras feministas têm trabalhado na direção de romper com as perspectivas dualistas, como Alaimo e Hekman (2008), Hird (2009), Hird e Roberts (2011), Kirby e Wilson (2011).

3 Por uma questão de manutenção da confidencialidade dos dados, conforme acordado, todas as informações que poderiam remeter à identificação dos/as participantes da pesquisa foram omitidas.

4 Estes resultados atribuídos aos implantes hormonais têm sido bastante destacados em matérias publicadas na imprensa brasileira, como argumentam Manica e Nucci (2017:103): "Além de garantirem a contracepção, os implantes teriam como efeitos secundários a diminuição da celulite, a perda de peso e ganho de massa muscular, o aumento da libido, a redução da acne, a amenorreia (ausência de menstruação) e, consequentemente, a redução de problemas de humor relacionados à menstruação, como a chamada TPM, tensão pré-menstrual". Estariam, dessa forma, próximos das chamadas drogas de estilo de vida, associadas mais a aprimorar performances e atender às exigências relativas à aparência, ao desempenho e às condições específicas do que a tratar doenças (Dumit 2012). Nucci (2012) ressalta que a própria pílula anticoncepcional, pela forma como é promovida e consumida, assumiria esta característica.

5 Há um longo debate acerca das potentes inspirações teóricas de Butler e como teria dado, ou não, a devida atenção à agência da matéria, especialmente no que se refere ao corpo. Nessa direção, especialmente considerando os estudos que envolvem ciência e tecnologia desde uma perspectiva feminista, ver, por exemplo, Barad (1998) e Herzig (2004), Sieben (2011), Roberts (2015).

6 Preciado (2013), na busca por um uso "farmacopornográfico" da testosterona, relata sua própria experiência do que seria um uso contestatório e subversivo deste hormônio. Contudo, parece-me que, quando descreve os efeitos da testosterona no próprio corpo, não apenas os associa diretamente a atributos tradicionalmente considerados masculinos em nossa sociedade (como capacidade produtiva, lucidez, energia física, desejo sexual intensos), como também parece conceder uma agência isolada ou per si à substância: "Então, uma extraordinária lucidez se instala, gradualmente, acompanhada por uma explosão do desejo de foder, andar, sair por toda parte na cidade. Este é o clímax em que a força espiritual da testosterona se mistura com o meu sangue. Absolutamente todas as sensações desagradáveis desaparecem" (Preciado 2013:21. Tradução minha.). 
7 Os chamados hormônios biodênticos têm aparecido no mercado de forma crescente, especialmente após as polêmicas envolvendo a reposição hormonal (TRH) no início dos anos 2000. Toda a retórica de sua promoção envolve a ideia de que sua composição seria idêntica aos hormônios produzidos pelo próprio organismo e que, portanto, seriam um recurso mais natural. Acerca dos debates envolvendo a TRH, ver o excelente trabalho de Faro (2016). Sobre a procura de recursos "naturais" e alternativos para a reposição hormonal, especialmente fitoterápicos, consultar o artigo de Sá (2012).

8 O uso de hormônios com fins de "prevenir" ou "retardar" o envelhecimento deve ser contextualizado no quadro mais amplo de investimentos da biomedicina no controverso campo do "antienvelhecimento", como discutem os trabalhos de Rougemont (2017) e Leitão e Pedro (2014).

9 Para uma história detalhada do desenvolvimento dos implantes hormonais no Brasil, inclusive com este apelo de suspender a menstruação e o papel proeminente de Elsimar Coutinho, ver Manica (2009). Especificamente a respeito das controvérsias em torno do implante contraceptivo Norplant ${ }^{\circledR}$ no Brasil, consultar Pimentel et al. (2017).

10 Um médico ginecologista entrevistado nesta pesquisa, após descrever os imensos benefícios associados ao uso de testosterona, especialmente em relação ao desejo sexual, afirmou: "As pessoas [dizem] 'ah, vai dar câncer'. Sim, vai dar câncer, tudo dá câncer". Faço referência a esta informação aqui porque indica como este tipo de raciocínio elaborado por Márcia também está presente entre alguns/algumas médicos/as que prescrevem o uso dos tratamentos hormonais. 


\section{Referências bibliográficas}

ABRAHAMSSON, Sebastian; BERTONI, Filippo; MOL, Annemarie; MARTÍN, Rebeca Ibáñez. 2015. "Living with omega-3: new materialism and enduring concerns". Environment and Planning D: Society and Space, 33:4-19.

ALAIMO, Stacy; HEKMAN, Susan. 2008. Material feminisms. Bloomington and Indianapolis: Indiana University Press.

BARAD, Karen. 1998. "Getting real: technoscientific practices and the materialization of reality". Differences, 10(2):87-128.

2007. Meeting the universe halfway: quantum physics and the entanglement of matter and meaning . Durham: Duke University Press. 2003. "Posthumanist performativity: toward an understanding of how matter comer to matter". Signs: Journal of Women in Culture and Society, 28(3):801-831.

BUTLER, Judith. 1990. Gender trouble: feminism and the subversion of identity. New York: Routledge.

CLARKE, Adele E.; SHIM, Janet; MAMO, Laura; FOSKET, Jennifer; FISHMAN, Jennifer (eds.). 2010. Biomedicalization: technoscience and transformations of health and illness in the U.S. Durham: Duke University Press.

DUMIT, Joseph. 2012. Drugs for life: how pharmaceutical companies define our health. Durham and London: Duke University Press.

FARO, Livi Ferreira Testoni de. 2016. Mulher com bigode nem o diabo pode: um estudo sobre testosterona, sexualidade feminina e biomedicalização. Tese de Doutorado em Saúde Coletiva, Universidade do Estado do
Rio de Janeiro.

HARAWAY, Donna. 1995. "Saberes localizados: a questão da ciência para o feminismo e o privilégio da perspectiva parcial". Cadernos Pagu, 5:07-41.

HERZIG, Rebecca. 2004. "On performance, productivity, and vocabularies of motive in recent studies of science". Feminist Theory, 5(2):127-147.

HIRD, Myra J. 2009. "Feminist engagements with matter". Feminist Studies, 35(2):329-346.

HIRD, Myra J.; ROBERTS, Celia. 2011. "Feminism theorises the nonhuman". Feminist Theory, 12(2):109-117.

HOBERMAN, John. 2005. Testosterone dreams. Rejuvenation, aphrodisia, doping. Berkeley: University of California Press.

KIRBY, Vicki; WILSON, Elizabeth A. 2011. "Feminist conversations with V. Kirby and E. A. Wilson". Feminist Theory, 12(2):227-234.

LEITAO, Antônio Nogueira; PEDRO, Rosa Maria Leite Ribeiro. 2014. "Medicina antienvelhecimento: notas sobre uma controvérsia sociotécnica". História, Ciências, Saúde - Manguinhos, 21(4):1361-1378

MANICA, Daniela; NUCCI, Marina. 2017. "Sob a pele: implantes subcutâneos, hormônios e gênero". Horizontes Antropológicos, 23(47):93-129.

MANICA, Daniela. 2009. Contracepção, natureza e cultura: embates e sentidos na etnografia de uma trajetória. Tese de Doutorado em Antropologia Social, Universidade Estadual de Campinas.

MARSHALL, Barbara. 2009. "Sexual medicine, sexual bodies and the "pharmaceutical imagination'". Science as culture, 18(2):133-49.

MARTIN, Emily. 2006. "The pharmaceu- 
tical person". BioSocieties, 1:273-287. MOL, Annemarie. 2002. The body multiple: ontology in medical Practice. Durham: Duke University Press. . 2008. "I eat an apple: on theorizing subjectivities". Subjectivity, 22:28-37.

. 2012. "Mind your plate! The ontonorms of Dutch dieting". Social Studies of Science, 43 (3):379-396.

NUCCI, Marina. 2012. "Seria a pílula anticoncepcional uma droga de 'estilo de vida'? Ensaio sobre o atual processo de medicalização da sexualidade". Sexualidade, Saúde e Sociedade, 10:124-139.

OUDSHOORN, Nelly. 1994. Beyond the natural body: an archeology of sex hormones. London: Routledge.

PIMENTEL, Ana Cristina de Lima; JANOTTI, Cláudia Bonan; GAUDENZI, Paula Gaudenzi; TEIXEIRA, Luiz Antonio da Silva. 2017. "A breve vida do Norplant ${ }^{\circledR}$ no Brasil: controvérsias e reagregações entre ciência, sociedade e Estado". Ciência e Saúde Coletiva, 22(1):43-52.

PRECIADO, Beatriz. 2013. Testo junkie: sex, drugs, and biopolitics in the pharmacopomographic era. New York: Feminist Press/ City University of New York.

ROBERTS, Celia. 2007. Messengers of sex: hormones, biomedicine and feminism. New York: Cambridge University Press.

. 2015. Puberty in crisis: the sociology of early sexual development. New York: Cambridge University Press.

ROHDEN, Fabíola. 2008. "O império dos hormônios e a construção da diferença entre os sexos". História, Ciências, Saúde-Manguinhos, 15:133-152.

. 2011. "'O homem é mesmo a sua testosterona': promoção da andropausa e representações sobre sexualidade e envelhecimento no cenário brasileiro". Horizontes Antropológicos, 17(35):161-196.

. 2017. "Sexual desire, testosterone and biomedical interventions: managing female sexuality in 'ethical doses'". Vibrant, 14 (3):1-12.

ROSE, Nikolas. 2007. The politics of life itself: biomedicine, power, subjectivity in the twenty-first century. Princeton: Princeton University Press.

ROUGEMONT, Fernanda. R. 2017. "O tempo no corpo: envelhecimento e longevidade na perspectiva anti-aging". Revista da Universidade Federal de Minas Gerais, 23:36-61.

SÁ, Ivone Manzali de. 2012. "'Fito-hormônios': ciência e natureza no tratamento do climatério". Physis: Revista de Saúde Coletiva, 22(4):1503-1522.

SANABRIA, Emilia. 2009. "Le médicament, un objet evanescent: essai sur la fabrication et la consommation des substances pharmaceutiques". Techniques \& Culture, 52/53:168-189. . 2016. Plastic bodies: sex hormones and menstrual suppression in Brazil. Durham and London: Duke University Press.

SIEBEN, Anna. 2011. "Heteronormative pheromones? A feminist approach to human chemical communication". Feminist Theory, 12(3):263-280. 
"OS HORMÔNIOS TE SALVAM

DE TUDO": PRODUÇÃO

DE SUBJETIVIDADES E

TRANSFORMAÇÕES CORPORAIS COM O USO DE RECURSOS BIOMÉDICOS

\section{Resumo}

Este artigo discute a produção de subjetividades e transformações corporais que ocorrem a partir do uso de recursos biomédicos. O fio condutor é a entrevista de uma usuária de implante hormonal. Foi concedida no escopo de um projeto que compreendeu a realização de entrevistas com médicos/as e pacientes/consumidoras de tratamentos hormonais, observações em eventos e análise de documentos. O caso ilustra a emergência de um novo tipo de "paciente-especialista-consumidor/a", como tem sido descrito/a na bibliografia sobre os processos de biomedicalização da sociedade. Contudo, argumento que, para além desta caracterização, serve para problematizar o estabelecimento de fronteiras predefinidas entre os supostos fatores materiais e discursivos. Considerando a narrativa da entrevistada, percebe-se que a subjetividade produzida é dependente da atuação do implante hormonal, ao mesmo tempo em que o implante exige uma série de investimentos para produzir os efeitos esperados. Isto remete à necessidade de uma abordagem analítica que privilegie os diferentes processos de materialização implicados.

Palavras-chave: Biomedicalização, Subjetivação, Hormônios, Gênero, Processos de materialização.

\section{"HORMONES SAVE YOU FROM EVERYTHING": PRODUCTION OF SUBJECTIVITIES AND BODILY TRANSFORMATIONS WITH THE USE OF BIOMEDICAL RESOURCES}

\section{Abstract}

This article discusses the production of subjectivities and bodily transformations related to the use of biomedical resources. Its guiding thread is an interview with a woman who is a hormonal implant user. This interview was carried out within the scope of a project that included interviews with physicians and patients/ consumers of hormonal treatments, as well as observations at events and analyses of documents. The case illustrates the emergence of a new type of "patient-specialist-consumer", as has been described in the literature on the biomedicalization of society. Moreover, it serves to problematize the establishment of pre-defined boundaries between the supposed material and discursive factors. Considering the narrative of the interviewee, the subjectivity produced is dependent on the performance of the hormonal implant, at the same time that the implant requires a series of investments to produce the expected effects. This underscores the need for an analytical approach that highlights the different processes of materialization involved.

Key words: Biomedicalization, Subjectivation, Hormones, Gender, Process of materialization. 


\section{"LAS HORMONAS TE SALVAN \\ DE TODO": PRODUCCIÓN \\ DE SUBJETIVIDADES $Y$ \\ TRANSFORMACIONES CORPORALES \\ CON EL USO DE RECURSOS \\ BIOMÉDICOS}

\section{Resumen}

Este artículo discute la producción de subjetividades y transformaciones corporales que ocurren a partir del uso de recursos biomédicos. El hilo conductor es una entrevista con una usuaria de implante hormonal, concedida en el contexto de un proyecto que incluía entrevistas con médicos/as y pacientes/consumidoras de tratamientos hormonales, observación en eventos y análisis de documentos. El caso ilustra la emergencia de un nuevo tipo de "paciente-especialista-consumidor/a", como ha sido descrito/a en la bibliografía sobre procesos de biomedicalización de la sociedad. No obstante, argumento que, más allá de esta caracterización, el caso sirve para problematizar el establecimiento de fronteras predefinidas entre los supuestos factores materiales y discursivos de tales procesos. Al considerar la narrativa de la entrevistada, se percibe que la subjetividad producida depende de la actuación del implante hormonal y, a su vez, el implante le exige comprometerse con una serie de acciones para producir los efectos esperados. Esto remite a la necesidad de un abordaje analítico que privilegie los diferentes procesos de materialización implicados. Palabras clave: Biomedicalización, Hormonas, Subjetividad, Género, Procesos de materialización. 
